ANKAD E-ISSN:2587-0491

\author{
Araştırma Makalesi/Research Article
}

\title{
Salda Gölü Havzası’nda İklim Koşullarındaki Değişikliğin Etkilerinin Belirlenmesi ${ }^{1}$
}

\section{Safiye Kübra ARITÜRK iD 2 - Beyza USTAOĞLU ${ }_{3}$}

${ }^{2}$ Yüksek Lisans Öğrencisi, Sakarya Üniversitesi, Sosyal Bilimler Enstitüsü Coğrafya Anabilim Dalı, Sakarya email:kubra.ariturk@ogr.sakarya.edu.tr

${ }^{3}$ Doç. Dr., Sakarya Üniversitesi, Fen Edebiyat Fakültesi Coğrafya Bölümü, Sakarya, e-mail: bustaoglu@ sakarya.edu.tr,

\section{Anahtar Kelimeler}

İklim değişikliği, Salda Gölü, Mann Kendall Sira Korelasyon Testi, uzaktan algılama, mekânsal analiz.

\section{Keywords}

Climate change, Lake Salda, Mann Kendall Rank Correlation Test, remote sensing, spatial analysis.

\section{Sorumlu yazar/Corresponding Author}

Beyza Ustaoğlu, Doç. Dr., Sakarya Üniversitesi, Fen Edebiyat Fakültesi Coğrafya Bölümü, Sakarya

Email: bustaoglu@ sakarya.edu.tr,

Geliş/Received: 29.09 .2020

Kabul/Accepted: 14.11 .2020

\begin{abstract}
Öz
Bu çalışmanın amacı, Türkiye'de önemli biyoçeşitlilik alanı olarak kabul edilen ve hassas bir ekosisteme sahip sulak alan olan Salda Gölü Havzası'nda iklim koşullarındaki değişikliğin etkilerinin belirlenmesidir. Çalışma alanı olan Salda Gölü Türkiye'nin güneybatısında, Göller Yöresi'nde yer almaktadır. İklim koşullarındaki değişikliğin göl havzası üzerindeki etkisini ortaya çıkarmak için a.) Burdur, Tefenni ve Acıpayam meteoroloji istasyonlarının 19702019 yıllarına ait yıllık ortalama sıcaklık ve yıllık toplam yağış verilerine Doğrusal Trend ve Mann Kendall Sıra Korelasyon Testi b.) Alan değişimini belirlemeye yönelik 1972 yılı Eylül ayı Landsat ERTS-1, 1984 yılı Landsat 5 TM, 1990 yılı Landsat 5 TM, 2000 yılı Landsat 7 ETM+, 2010 yılı Landsat 5 TM, ve 2019 yılı Ekim aylarına ait Landsat 8 OLI uydu görüntüleri kullanılarak coğrafi bilgi sistemleri ile mekânsal analizler c.) Uzun yillar yıllık ortalama ve Ekim ayı göl seviyesi verileri kullanılarak göl seviyesinin değişim grafiği oluşturulmuştur. Elde edilen sonuçlara göre; 50 y1llık periyod boyunca yıllık ortalama sicaklıklarda istatistiksel olarak $\alpha=0.05$ anlamlılık seviyesinde artış eğilimi ve $\mathrm{u}(\mathrm{t})$ ve $\mathrm{u}^{\prime}(\mathrm{t})$ değerlerinin kesiştiği 2000'li yıllardan sonra sıcaklık eğilimlerinde artan yönde bir değişiklik tespit edilirken, yıllık toplam yağış tutarlarında istatistiksel olarak anlamlı bir sonuç tespit edilememiştir. CBS ile mekânsal analiz sonucunda 19722019 yılları arasında göl yüzey alanında \% 4,6 oranında küçülme meydana geldiği gözlemlenmiştir. İklim verilerinin ve uydu görüntülerinin istatistiksel analizi ve arazi çalışmaları sonucunda Göller Yöresi'nde yer alan birçok göl gibi Salda Gölü'nün de iklim değişikliği tehlikesiyle karşı karşıya olduğu tespit edilmiştir.
\end{abstract}

\footnotetext{
${ }^{1} \mathrm{Bu}$ makale birinci yazarın ikinci yazar danışmanlığında hazırladığg Yükssek Lisans tezinden üretilmiştir.
} 


\title{
Determination of Climatic Conditions Changes Impacts on Lake Salda Basin
}

\begin{abstract}
The purpose of this study is to examine the climate conditions changes impact on Lake Salda in Turkey, a wetland with a vulnerable ecosystem that is considered a Key Biodiversity Area. Lake Salda, the area of the study, is located in the Lakes Region in southwestern of Turkey. To reveal the impact of climate change on the lake basin a.) Linear Trend and Mann-Kendall Rank Correlation Test for average temperature and total precipitation data of Burdur, Tefenni and Acipayam meteorological station for the Years 1970-2019 b.) Spatial analysis and GIS for determining the areal change using the October 1972 Landsat ERTS-1, September 1984 Landsat 5 TM, 1990 Landsat 5 TM, 2000 Landsat 7 ETM+, 2010 Landsat 5 TM and 2019 Landsat 8 OLI satellite images c.) Lake level change graph has been created using annual average and October lake level data for many years. According to results, the trend of increasing statistical significance level of $\alpha=0.05$ in annual average temperatures over the 50 year period and was detected an increasing change in temperatures trend after the year of 2000 when $u(t)$ and $u^{\prime}$ (t) values intersected. Despite this, no significant trend or change in the annual total precipitation amounts was able to be detected. As a result of Spatial Analysis with GIS, 4.6\% decrease was observed in the lake surface area between 1972-2019 and statistical analysis of the climate data and satellite images Lake Salda, like many of the lakes in the Lakes Region, has been determined to also be faced with the negative effects of climate change.
\end{abstract}

\section{GİRIŞ}

İklim koşullarındaki değişiklik arazi ve su kaynaklarını, bunların mekânsal ve zamansal dağılımlarını, suyun hidrolojik döngüsünü, su kalitesini ve dünyanın farklı bölgelerinde su kaynaklarına olan ihtiyacı etkilemektedir (IPCC, 2014). Artan sıcaklıklar başta ekolojik döngüler ile canlı ve cansız tüm varlıklar üzerinde doğrudan veya dolaylı olarak etkisini göstermeye başlamıştır. Dünyadaki toplam suyun \%96,6'sını okyanus ve denizlerdeki sular, \%3,4'ünü ise tatlı sular oluşturmaktadır. Tatlı suların \%69,3'u buzulların bünyesinde, \%30,3'si yeraltı suyu, $\% 0,35$ 'i yüzey suyu, $\% 0,04$ 'ü diğer sular olarak yer alır. Yüzey sularını ise $\% 87$ göller, \%11 bataklık ve sulak alanlar, \%2 oranında akarsular oluşturur (DKMP, 2013). Göl ve akarsuların dünyadaki tatlı su kaynakları içerisinde sadece \% 0,3'lük bir payının olması, Türkiye'nin Akdeniz iklim kuşağında yer alması ve sıcaklıkların artış eğiliminde olması göl ve akarsuların korunmasının ne derece önemli olduğu ortaya koymaktadır. BM Dünya Meteoroloji Örgütü'nün (WMO) açıklamasına göre 2019 yılı dünya genelinde son 140 yıl içerisinde en sıcak ikinci yıl, Türkiye'de ise son 49 yıl içerisinde en sıcak dördüncü yıl olarak kayıtlara geçmiştir. 2020 yılı ise ekstrem olayların sıklığı ile devam etmektedir. Bu durum, Akdeniz Havzasında yer alan Türkiye ve çevresinde gelecekte iklimin uzun yıllar ortalamalarından daha sık sapma eğilimde olan ve ekstrem iklim olaylarının daha sık yaşanacağı (sel, şiddetli yağış, firtına, hortum olayı, sıcak hava dalgası, kuraklık vb.) bir iklimin görülme olasılığını arttırmaktadır (Baylan \& Ustaoğlu, 2020). Göller, dünyadaki canlılar için en önemli yaşam kaynaklarından biridir. Göller Yöresinde yer alan Salda Gölü ve çevresini de içinde barındıran 295,63 km²'lik alan, 14.03.2019 tarihli ve 824 sayılı karar ile Özel Çevre Koruma Bölgesi olarak ilan edilmiştir. 20 endemik tür ile biyoçeşitliliğin yüksek olduğu bir göldür. Bu endemik türler arasında Önemli Doğa Alanı ve Önemli Kuş Alanı şartlarını sağlayan Uluslararası Doğayı Koruma Birliği (IUCN)'nin koruma altına aldığı türler de bulunmaktadır. Bu sebeple göl, hem uluslararası hem de ulusal öneme sahip sulak alan konumundadır.

Yapılan arazi çalışmasında da görüldüğü üzere berrak suyu ve açık turkuaz rengiyle son yıllarda ilgi odağı olmuştur (Foto:1). Ayrıca Mars'taki Jezero Kraterinde bulunan karbonatlara ve biriktirme yapılarına benzer özellikler içermesi nedeniyle dünyada bilinen tek göldür (NASA, 2020). 
Foto 1: a) Salda Gölü batısından Kale Tepe’ye bakış, b) Killi manyezit çökelleri c) Kıyı kesime yakın güncel hidromanyezit stromatolit oluşumları d) Beyaz Adalar Plajı'ndaki Huntit minerali yatakları.

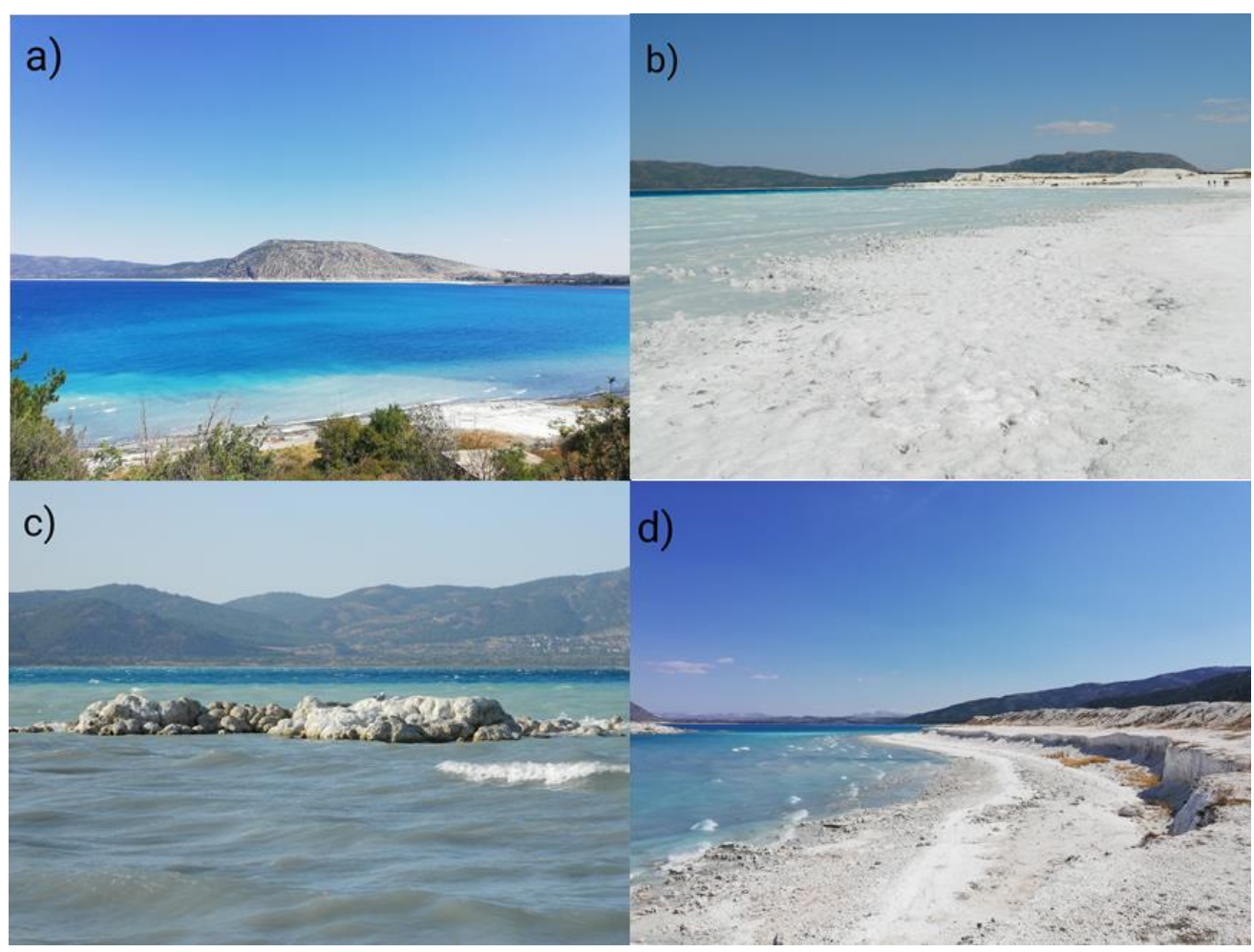

Yapılan literatür çalışmasında Salda gölü ile ilgili çalışmaların, genellikle hidromanyezit oluşumlar ve stromatolitler ile ilgili olduğu görülmüştür. Bu anlamda ilk çalışmalar Schmidt (1987), Braithwaite ve Zedef (1994) tarafından yapılmıştır (Schmidt, 1987, Braithwaite \& Zedef, 1994; Akt. Kazanc1, 2004, s.152). Son yıllarda yapılan çalışmalar ise gölden alınan çökelti örnekleriyle ilgili çalışmalardır (Danladia \& Ön, 2015; Çaldırak vd., 2017). Salda Gölü için kavramsal su bütçe modelinin uygulandığı çalışmada göl suyu seviyesinin 1999-2015 yılları arasındaki farkları belirlenmiştir (Varol vd., 2018). Buna göre minimum fark $0.35 \mathrm{~cm}$ ve maksimum fark $1.59 \mathrm{~m}$ olarak bulunmuştur. Göl seviyesinin gerilemesiyle, SPI değerleri dikkate alınarak Burdur ve Tefenni istasyonlarında 2006-2008 yılların arasında orta ve şiddetli kurak dönem olduğu tespit edilmiştir. Fakat göl seviyesinin tekrar yükselmesi ile 2008-2010 arası dönem normal yağış dönemleri olarak tanımlanmıştır. Salda Gölü'nü besleyen yeraltı sularının çevresel etkenlere duyarlılığının CBS yöntemleriyle incelendiği çalışmada ise tarımsal faaliyetlerin ve hayvancılığın yoğun olduğu alanlardaki kuyularda nitrat yoğunlaşma değerleri yüksek olduğu belirtilmiştir (Varol vd., 2020). Ayrıca Salda Gölü’nün, yeraltı suyu kirliliğine karşı orta ve yüksek hassasiyete sahip bölgede yer aldığı tespit edilmiştir. Akiferlerin bulunduğu alanlarda zararlı insan faaliyetlerine ve tarımsal kirlilik meydana getiren unsurlara izin verilmemesi gerektiği vurgulanmıştır. İklim değişikliğine karşı en hassas alanların başında göller gelmektedir. İklimin etkisinin büyük oranda hissedildiği ve sıcaklıkların artış gösterdiği alanlarda göller büyük risk altındadır. Bu sebeple göllerle ilgili birçok çalışma yapılmaktadır (Yiğitbaşığlu, 1995; Kazanc1 vd., 2008; Delju vd., 2012; Orhan, 2014; Doulgeris \& Kapsomenakis, 2016; Kale vd., 2018).

Mann-Kendall Sıra Korelasyon Testi, iklim değişikliği ve etkilerini belirleyen çalışmalarda en çok kullanılan yöntemlerden birisidir (Türkeş, 1996; Yue vd., 2002; Tabari vd., 2011; Ustaoğlu, 2013). İklim değişikliğinin ve antropojenik unsurların etkisiyle son yıllarda Türkiye'de birçok göl kuruyarak yok olmuş ya da alanlarında büyük ölçüde küçülme meydana gelmiştir. Salda Gölü'nün de içinde bulunduğu Göller Yöresi farklı nitelik ve özelliğe sahip önemli gölleri 
içinde barındırmaktadır. Yapılan çalışmalar Göller Yöresi göllerinin yıllar içinde değişime maruz kaldığını ortaya koymuştur. Eber ve Akşehir gölleri gibi sığ göller kurak geçen yaz dönemlerinde kurumaktadır. Eğirdir ve Beyşehir göllerinin su seviyesinde düşüşler meydana gelmiştir (Kantarc1, 2009). Bu bölgede yer alan birçok göl iklim değişikliği ve etkileri nedeniyle tehlike altında olup Salda Gölü de bu göllerden biridir. Bu çalışmanın amacı Salda Gölü havzasında iklim koşullarında meydana gelen değişikliğin etkilerini iklim verileri ve uydu görüntüleri kullanılarak istatistiksel yöntemler ve arazi çalışmalarıyla tespit etmek, elde edilen bulguları karar vericiler ile paylaşarak iklim değişikliğine uyum ve adaptasyon sürecinin nasıl olması gerektiği yönünde bilgi sunabilmektir.

\section{1. Çalışma Alanı}


boylamları arasında yer almaktadır. Akdeniz Bölgesi’nin Göller Yöresinde 260 km² izdüşüm alana sahip kapalı havza özelliği gösteren karstik bir göldür. Bu alanın yaklaşık $45 \mathrm{~km}^{2}$ 'sini göl suları oluşturmaktadır (Çetin, 2002). Göl tektonik hareketler ile meydana gelmiş ve deniz seviyesine göre yüksekliği $1140 \mathrm{~m}$ 'dir. (Kazancı vd., 2004). Genişliği yaklaşık $6.8 \mathrm{~km}$, uzunluğu ise 9.186 km'dir (OSİB, 2013). Yer yer 200 m'yi bulan çöküntülerin bulunduğu gölde su derinliği 0-104 m arasında değişmektedir (Kazancı vd., 2004).

Kapalı havza özelliği gösteren göl sürekli ve mevsimlik akışlı dereler ve yeraltı suyuyla beslenmektedir. Gölü besleyen dereler arasından en bilinenleri Killik Deresi, Köpekçay, Kurucam, Böğrüdelik, Değirmendere ve Karakova (Salda) Deresidir. Gölü besleyen kaynakların çoğunluğu iklim koşullarına (yağış, sıcaklık, buharlaşma vb.) ve göle giriş yapan kaynaklara bağlıdır. Gölün sahil kesimlerinde hidromanyezit çökeltilerden oluşan teraslar mevcuttur (Braithwaite \& Zedef, 1995). Kalsiyum karbonatın su ile olan etkileşimi sonucu killi, küçük boyutlu kimyasal ayrışma ürünleri ortaya çıkmaktadır (Fural vd., 2019). Göle gösterilen yoğun ilginin sebebi ise; killi ve küçük boyuttaki materyallerin depolanması ve ufalanması sonucunda göle özgü beyaz kumların oluşması, bu kumların yer aldığı kıyı kesimlerin diğer göllerden farklı olarak turkuaz renkli görünüm sağlamasıdır. Bol mineral varlığı gölün soğuk mevsimlerde donmasını engeller. Böylece göç yolları üzerinde bulunan göl, kış mevsiminde konaklayan kuş türlerine yaşam alanı olabilmektedir (Kazancı vd., 2004).

Çalışma alanında Akdeniz iklim koşulları görülmektedir. Burdur Meteoroloji İstasyonundan alınan veriler incelendiğinde; uzun yıllar yıllık ortalama sıcaklığg $13,2{ }^{\circ} \mathrm{C}$ 'dir. En soğuk ay ortalama sicaklığ $2,5^{\circ} \mathrm{C}$, en sicak ay ortalama sıcaklığ $24,5^{\circ} \mathrm{C}$ 'dir. Yıllık ortalama yağış 428 mm'dir. Gölün çevresindeki bitki örtüsünü genel olarak Kızılçam, Anadolu Karaçamı ve Ardıç türleri ile karışık ormanlar ve meşe toplulukları oluşturmaktadır (Ustaoğlu \& Uzun, 2018) (Şekil 1). 
Şekil 1: Çalışma alanının lokasyon haritası

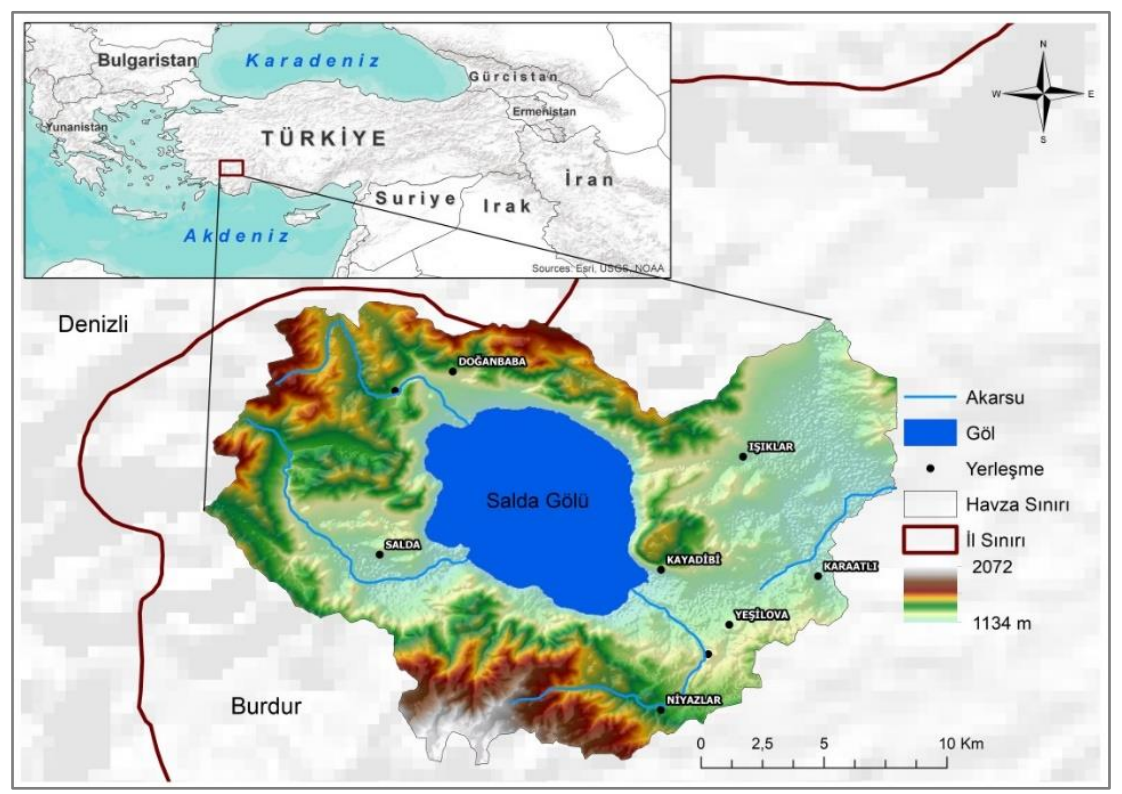

\section{MATERYAL ve YÖNTEM}

İlk aşama olarak Salda Gölü'nün çevresinde yer alan, uzun dönem ve sürekli veri kaydı bulunan Burdur (merkez), Tefenni ve Acıpayam meteoroloji istasyonlarına ait 1970-2019 y1lları aras1 yıllık ortalama sıcaklık ve yıllık toplam yağış verilerine Doğrusal Trend ve Mann Kendall Sıra Korelasyon Testi uygulanmıştır.

Çalışmanın ikinci aşamasında USGS (United States Geological Survey)'den 03 Eylül 1972 Landsat ERTS-1, 27 Ekim 1984 Landsat 5 TM, 12 Ekim 1990 Landsat 5 TM, 15 Ekim 2000 Landsat 7 ETM+, 3 Ekim 2010 Landsat 5 TM ve 12 Ekim 2019 tarihli Landsat 8 OLI uydu görüntüleri elde edilmiştir. Görüntüler ArcMap 10.2 ortamında Spatial Analyst ve Conversion Tools kullanılarak CBS'de Mekânsal Analiz ve yüzey alanı değişimi analizi yapılmıştır. Son olarak Varol (2018)'dan ve TMMOB (2020) raporundan elde edilen 1998-2015 y1lları arasındaki aylık ve yıllık ortalama göl seviyesi verileri analiz edilerek Mann Kendall Sira Korelasyon Testi ve uydu görüntülerinin mekânsal analizi sonucu elde edilen verilerle karşılaştırılıp değerlendirilmiş ve çalışma ile ilgili bulgular elde edilmiştir (Şekil 2). 
Şekil 2: İş akışşseması

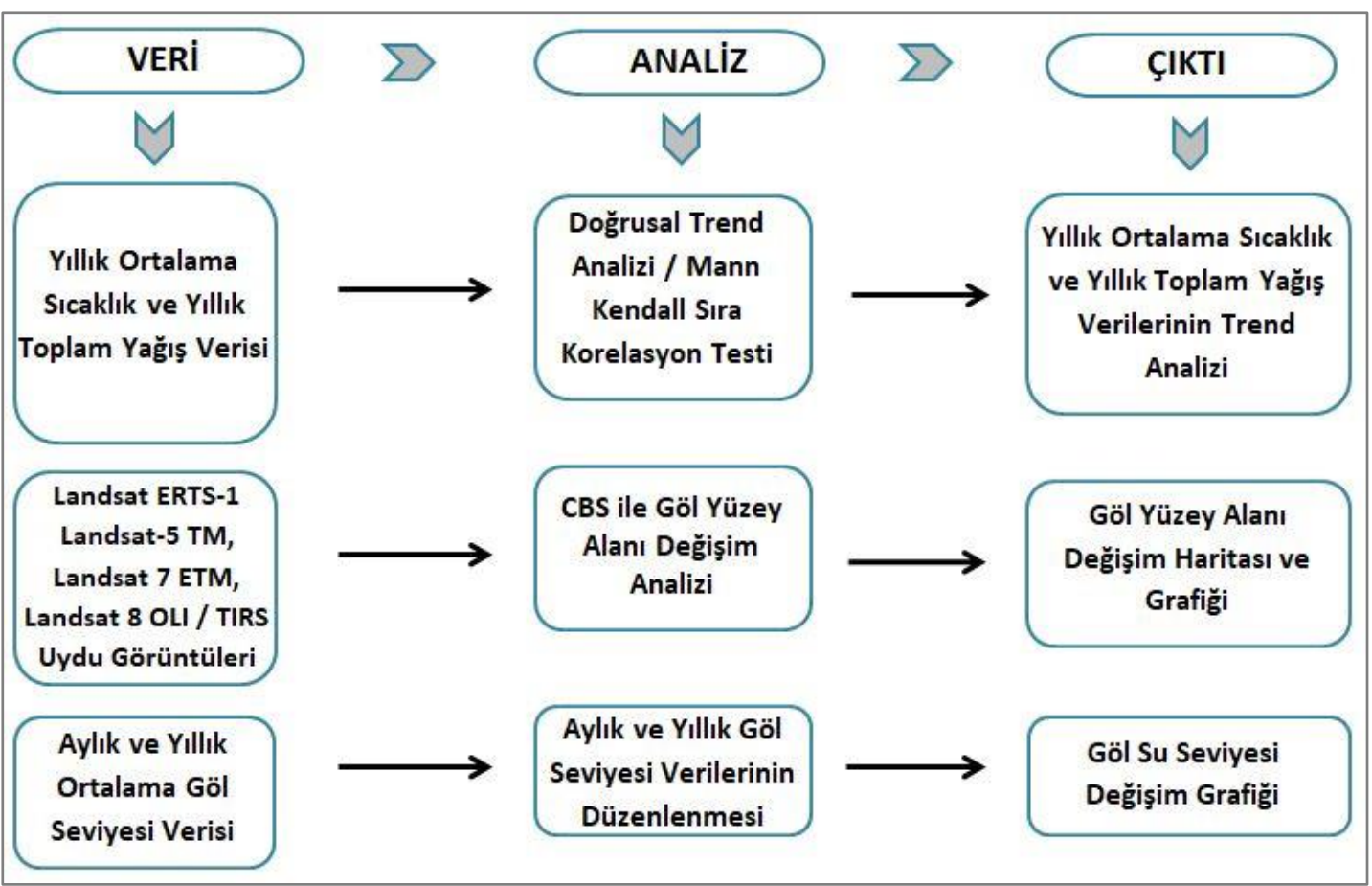

\subsection{Mann Kendall Sira Korelasyon Testi}

Parametrik olmayan sıra temelli Mann-Kendall istatistik testi, sıcaklık ve yağış verileri gibi iklim zaman serilerindeki trendin önem derecesini belirlemek için yaygın olarak kullanılmaktadır. Parametrik olmayan istatistiksel testlerin tercih edilmesinin nedeni, parametrik istatistiksel testlere göre iklim zaman serilerinde rastlanan normal dağılıma sahip olmayan veriler için daha uygun olduğunun düşünülmesidir. Mann Kendall sıra korelasyon metodu aşağıda anlatıldığ 1 şekilde uygulanır:

Mann Kendall testinde, $n$ uzunluğundaki yi serisinin her xi $(i=1, \ldots, n)$ elemanı için ni, j'nin i’yi takip edeceği şekilde (i>j) xi>xj olan elemanlarının sayısıdır. Testin trend istatistiği " $t$ " aşağıda verilen eşitlik ile hesaplanır:

$t=\sum_{n}^{i} n i$

t'nin ortalaması, varyansı ve trendi aşağıdaki eşitlikler ile gösterilir.

$E(t)=\frac{n(n-1)}{4}$

$\operatorname{var}(t)=\frac{n(n-1) \cdot(2 n+5)}{72}$ 
$u(t)=\frac{(t-E(t))}{\sqrt{\operatorname{var}(t)}}$

Trendin anlamlılık değerleri $\alpha=0.05$ veya $\alpha=0.01$ seviyelerinde değerlendirilebilir. Elde edilen $\mathrm{u}(\mathrm{t})$ değeri \pm 1.96 'nın arasında ise zaman serisinde bir trend olmadığ 1 kabul edilir. Eğer elde edilen değer \pm 1.96 aralığının dışında ise zaman serisinde bir trendin olduğu kabul edilebilir. Hesaplanan $\mathrm{u}(\mathrm{t})$ değerinin anlamlı olması durumunda, trendin yönünü ise sonucun işareti belirler; eğer sonuç pozitif işaretli ise artan, negatif işaretli ise azalan yönde bir trend olduğu kabul edilir. $\mathrm{u}(\mathrm{t})$ 'nin sıfıra yakın değerleri zamanla bir değişimin olmadığını gösterir. MannKendall trend testi, biri serinin başından diğeri ise serinin sonundan başlanarak iki istatiksel serinin hesaplanmasına dayalıdır. Bu seriler biri direkt eğri (direct $-\mathrm{u}(\mathrm{t}))$ diğeri de geriye doğru eğri (backward $-\mathrm{u}^{\prime}(\mathrm{t})$ ) olarak adlandırılan iki eğri formunda gösterilirler. $\mathrm{Bu}$ durumda iklimdeki değişimin başlangıcını işaret eden nokta, direkt eğri $u(t)$ ile geriye doğru eğri $u^{\prime}(t)$ arasındaki kesişime karşılık gelir. Serilerde anlamlı bir trend olmadığı durumlarda, direkt ve geriye doğru eğriler sıklıkla düzensiz/çapraşık birbirini birkaç kere altlı üstlü keserler (Ustaoğlu, 2012).

\subsection{CBS ile Göl Yüzey Alanı Değişim Analizi}

Su kaynaklarının, göl ve akarsuların alan ve kıyı çizgisi değişimini tespit etmek, elde edilen veriler sonucu önlemler almak, uzaktan algılama, coğrafi bilgi sistemleri teknolojilerindeki gelişmeler ve uydu görüntülerinin ulaş1labilir hale gelmesiyle daha nitelikli hale gelmiştir (İkiel \& Ustaoğlu, 2011). Su kaynaklarının yüzeysel analizleri ve bu kaynaklar hakkında bilgi toplanmasında CBS'nin sunduğu imkânlar analizlerin kolaylığı açısından yarar sağlamaktadır (Turoğlu \& Aykut, 2019). Çalışmada göl yüzey alanında meydana gelen değişimi belirlemek amacıyla uydu görüntüleri üzerine sırasıyla şu işlemler uygulanmıştır:

- Analiz için kullanılacak olan 03 Eylül 1972 tarihli Landsat ERTS-1, 27 Ekim 1984 tarihli Landsat 5 TM, 12 Ekim 1990 Landsat 5 TM, 15 Ekim 2000 Landsat 7 ETM, 3 Ekim 2010 Landsat 5 TM ve 12 Ekim 2019 tarihli Landsat 8 OLI uydu görüntülerinin bandları ArcMap 10.2 ortamında birleştirilerek kontrolsüz sınıflandırma yapılmıştır.

- Birleştirilen bandlar doğal renklendirme sıralamasına göre dizilmiştir. Spatial Analyst Tool kullanılarak yeniden sınıflandırma işlemi uygulanmıştır.

- Yeniden sınıflandırma sonucu oluşan raster veri Conversion Tools kullanılarak vektör veriye dönüştürülmüş ve çalışma alanı içerisinde yer alan unsurlar poligon şeklinde sınıflanmıştır.

- Göl alanının sınırlarını içeren poligonlar analizin yapıldığı her yıla ait göl sınırlarını ortaya çıkarmış ve haritalanmıştır.

- Ortaya çıkan göl sınırlarının alan hesabı için Calculate Geometry aracı kullanılarak her yıla ait göl yüzey alanının kaç $\mathrm{km}^{2}$ 'lik bir alana karşılık geldiği hesap edilerek karşılaştırılmıştır.

\subsection{Aylık ve Yıllık Göl Seviyesi Verilerinin Düzenlenmesi}

Göl seviyesi değişimini analiz etmek için Varol vd., (2018)'den ve Salda Gölü Raporu'ndan (TMMOB, 2020) 1998-2015 yıllarına ait aylık ve yıllık ortalama göl seviyesi verileri elde edilmiştir. Bu veri kaydı DSİ'nin D10G020 no'lu Salda Gölü Göl Gözlem İstasyonu'na ait verilerdir. Elde edilen veriler grafik üzerinde analiz edilmiş ve diğer verilerle uyumu karşıllaştırılmıştır. 


\section{BULGULAR ve TARTIŞMA}

Meteoroloji istasyonlarından elde edilen 1970-2019 yılları arasındaki ortalama sicaklık ve yıllık toplam yağış verilerine Doğrusal Trend ve Mann-Kendall Sıra Korelasyon testi uygulanmıştır (Tablo 1). Doğrusal trend işlemi sonucunda elde edilen grafikler incelendiğinde, Burdur, Acıpayam ve Tefenni istasyonlarının yıllık ortalama sıcaklık ve yıllık toplam yağış değerlerinde artış eğilimi olduğu görülmüştür (Şekil 3). Yıllık ortalama sıcaklık verilerindeki artış eğiliminin yıllık toplam yağış verilerine kıyasla daha yüksek olduğu tespit edilmiştir (Şekil 4).

Tablo 1: Meteoroloji istasyonları ve özellikleri

\begin{tabular}{l|l|l|l|l|l}
\hline İstasyon Adı & Enlem & Boylam & Yükseklik (m) & Periyod (Ort. Sıcaklık) & Periyod (Top. Yağış) \\
\hline Burdur & 37,72 & 30,29 & 957 & $1970-2019$ & $1970-2019$ \\
Tefenni & 37,18 & 29,46 & 1142 & $1970-2019$ & $1970-2011$ \\
Acıpayam & 37,43 & 29,34 & 941 & $1970-2019$ & $1970-2011$ \\
\hline
\end{tabular}

Şekil 3: Meteoroloji istasyonlarının yıllık ortalama sıcaklık verilerinin doğrusal trendi




Mann Kendall Sıra Korelasyon testi sonuçlarına göre Burdur $(\mathrm{u}(\mathrm{t})=4,43)$, Acıpayam $(\mathrm{u}(\mathrm{t})=$ $6,63)$ ve Tefenni $(\mathrm{u}(\mathrm{t})=3,76)$ istasyonlarının yıllık ortalama sıcaklık değerlerinde $\alpha=0.05$ anlamlılık düzeyinde (\%95 güven aralığı) istatistiksel olarak artan bir eğilim tespit edilmiştir. $\mathrm{u}(\mathrm{t})$ ve $\mathrm{u}^{\prime}(\mathrm{t})$ değerlerinin çakıştığı Burdur ve Tefenni Meteoroloji istasyonları

Şekil 4: Meteoroloji istasyonlarının yıllık toplam yağış verilerinin doğrusal trendi
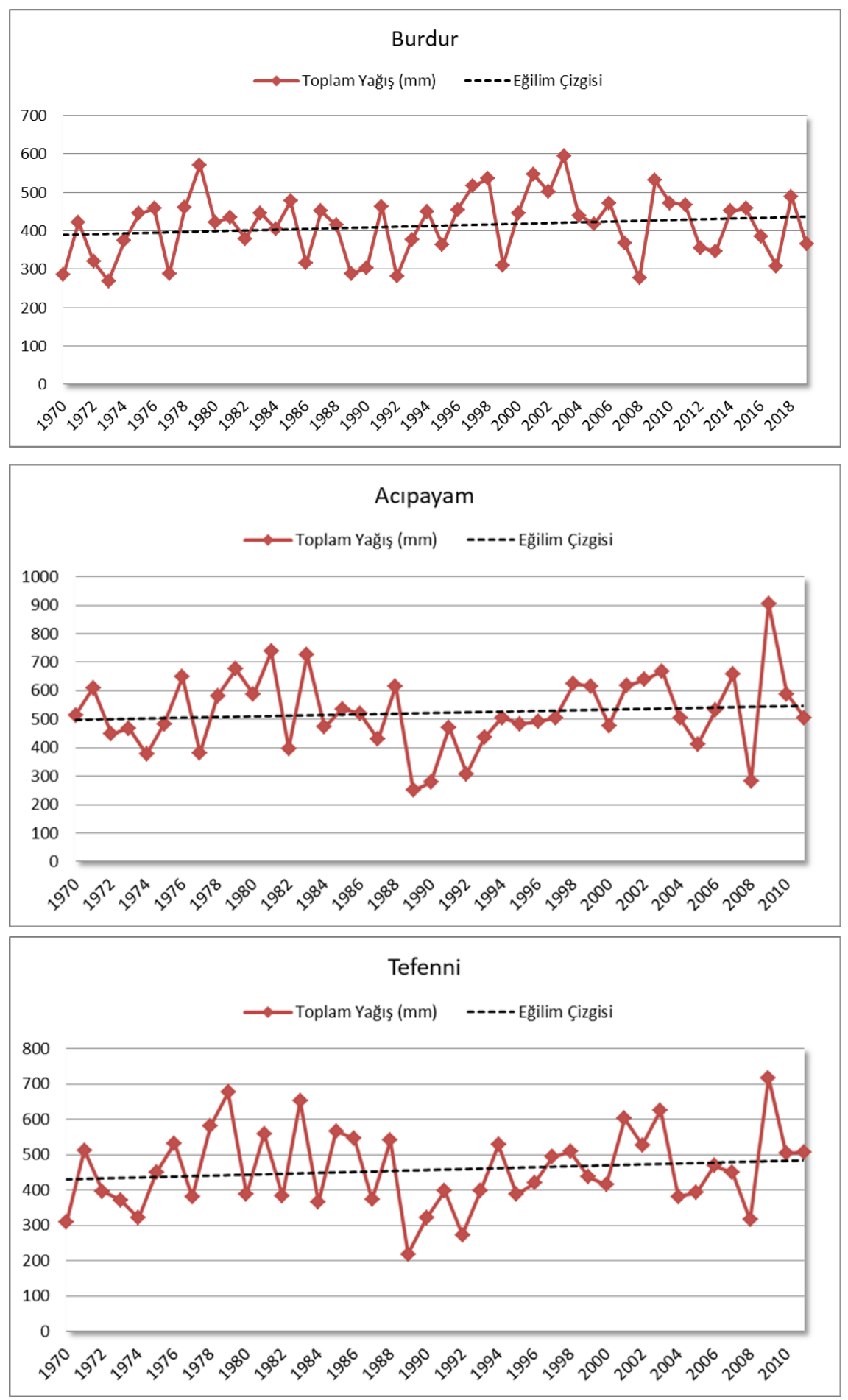

için 2006 yılı ve Acıpayam Meteoroloji istasyonu için 1998 y1lı, sıcaklık değerlerinde değişiminin başladığı yıl olarak belirlenebilir (Tablo 2). Sonuç olarak, 2000'li yıllardan itibaren çalışma alanında iklim koşullarında bir değişiklik olduğu istatistiksel olarak gözlemlenmektedir (Şekil 5). 
Tablo 2: Meteoroloji istasyonlarının 1970-2019 yılları arasındaki yıllık ortalama sıcaklık ve yıllık toplam yağış verilerine uygulanan Mann-Kendall sıra korelasyon testi istatistikleri

\begin{tabular}{|c|c|c|c|c|c|}
\hline \multicolumn{6}{|c|}{ Mann - Kendall Sira Korelasyon Testi (Ortalama Sicaklık) } \\
\hline İstasyon Adı & Zaman Serisi & $\mathbf{u}(\mathbf{t})$ & Trend $(\alpha=0.05 ; \% 95)$ & Trend Yılı & n Değerleri \\
\hline Burdur & Ortalama & 4,43 & Artan Trend & 2006 & 50 \\
\hline Tefenni & Ortalama & 3,76 & Artan Trend & 2006 & 50 \\
\hline Acıpayam & Ortalama & 6,33 & Artan Trend & 1998 & 50 \\
\hline
\end{tabular}

\section{Mann - Kendall Sıra Korelasyon Testi (Toplam Yağıș)}

\begin{tabular}{cccccc}
\hline İstasyon Adı & Zaman Serisi & $\mathbf{u}(\mathbf{t})$ & Trend $(\boldsymbol{\alpha}=\mathbf{0 . 0 5} ; \boldsymbol{\%} 95)$ & Trend Yılı & n Değerleri \\
\hline Burdur & Ortalama & 1,26 & Trend Yok & 1970 & 50 \\
Tefenni & Ortalama & 1,64 & Trend Yok & 1971 & 42 \\
Acıpayam & Ortalama & 1,59 & Trend Yok & 1978 & 42 \\
\hline
\end{tabular}

Şekil 5: Meteoroloji istasyonlarının yıllık ortalama sıcaklık verilerinin Mann Kendall Sıra Korelasyon Testi grafikleri

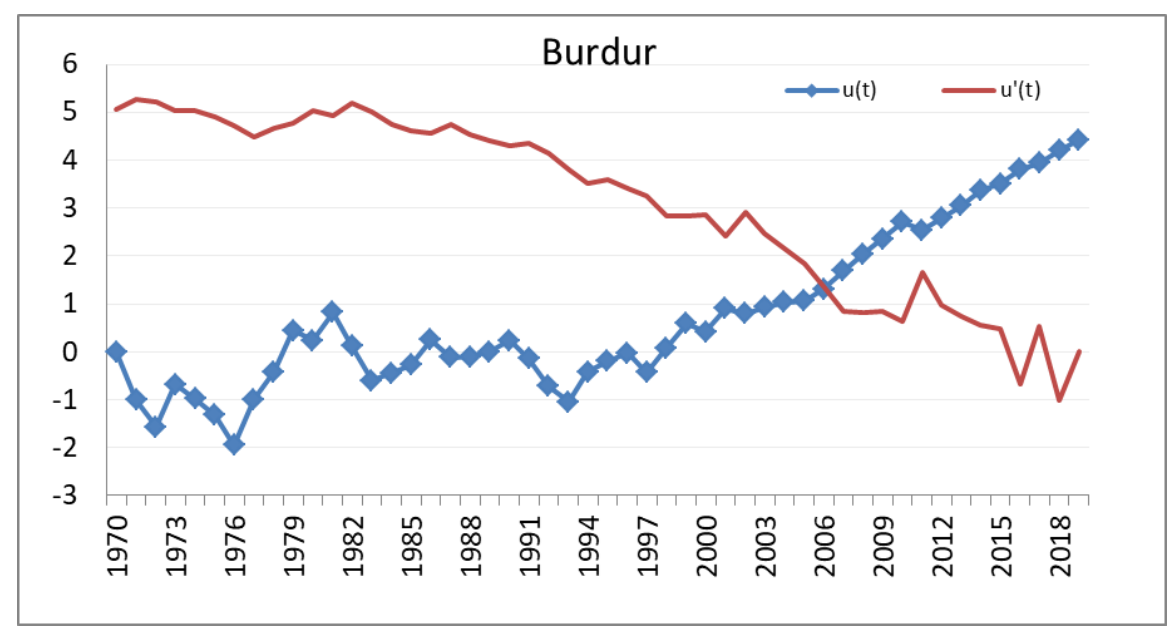



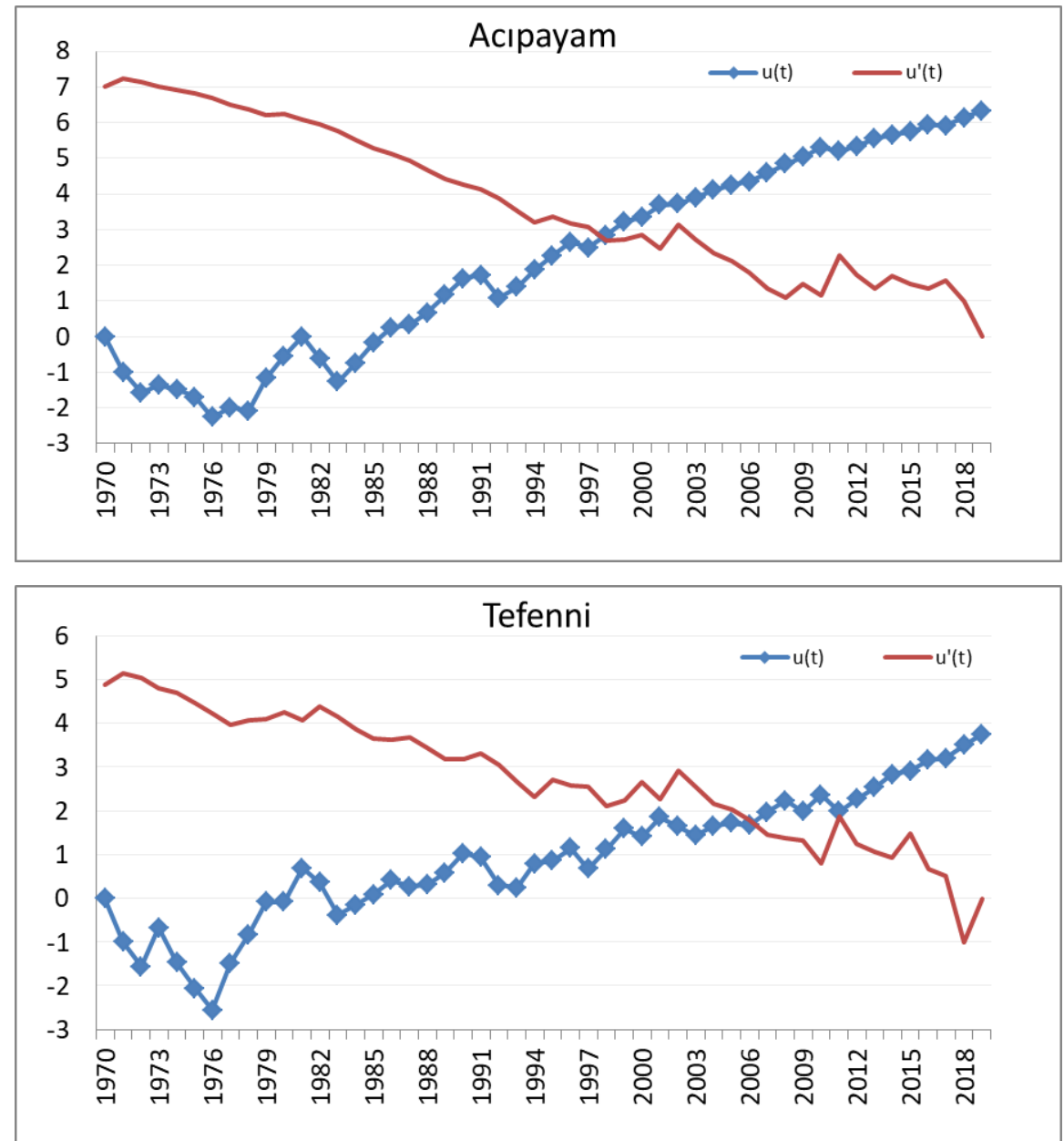

Mann Kendall Sıra Korelasyon Testi 'nin grafiklerinde eğriler birçok yerde ve karmaşık bir şekilde kesiştiği için, yağış verilerinin trend analizinde üç istasyon için de Burdur $(u(t)=1,26)$, Acıpayam $(\mathrm{u}(\mathrm{t})=1,59)$ ve Tefenni $(\mathrm{u}(\mathrm{t})=1,64) \alpha=0.05$ anlamlılık düzeyinde $(\% 95$ güven aralığ $)$ istatistiksel olarak anlamlı bir sonuç elde edilememiştir (Şekil 6).

Şekil 6: Meteoroloji istasyonlarının yıllık toplam yağış verilerinin Mann Kendall Sıra Korelasyon Testi grafikleri

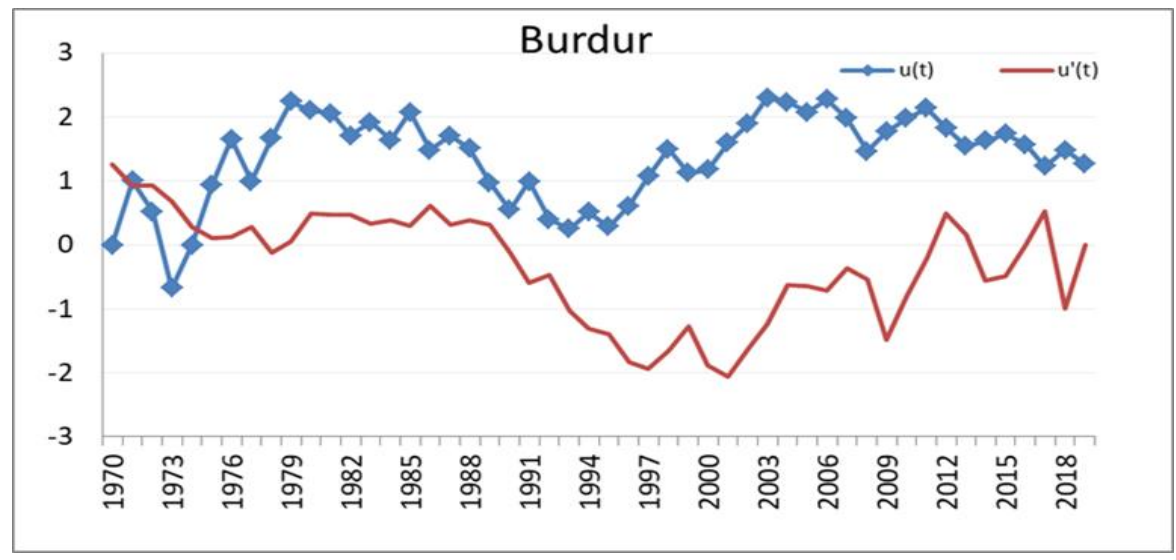



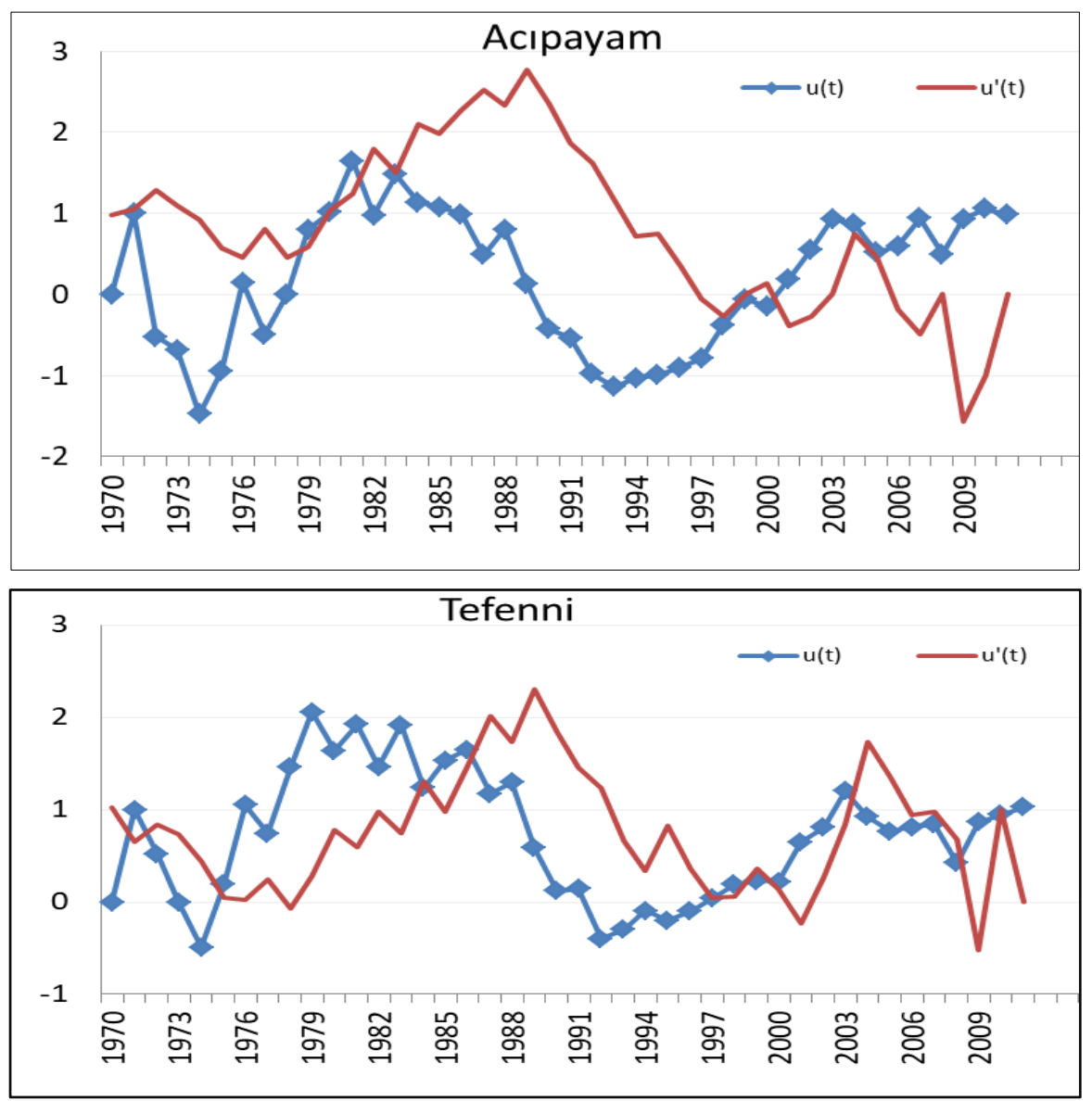

İkinci aşama olarak; 03 Eylül 1972 Landsat ERTS-1, 27 Ekim 1984 Landsat 5 TM, 12 Ekim 1990 Landsat 5 TM, 15 Ekim 2000 Landsat 7 ETM+, 3 Ekim 2010 Landsat 5 TM ve 12 Ekim 2019 tarihli Landsat 8 OLI uydu görüntülerinin kontrolsüz ve yeniden sinıflandırılması sonucu CBS'de mekânsal analiz ile göl sınırları elde edilmiştir. Bu sınırların alan hesabıyla da yüzey alanı değişimi karşılaştırılmıştır. Elde edilen sonuçlar doğrultusunda göl sınırlarında 1972-1984 yılları arasında büyüme, 1984-1990 yılları arasında küçülme, 1990-2000 y1lları arasında tekrar küçülme, 2000-2010 yılları arasında büyüme ve 2010-2019 yılları arasında küçülme gözlenmiştir (Şekil 7). 
Şekil 7: Salda Gölü’nün 1972-2019 yılları arasındaki sınır değişimi
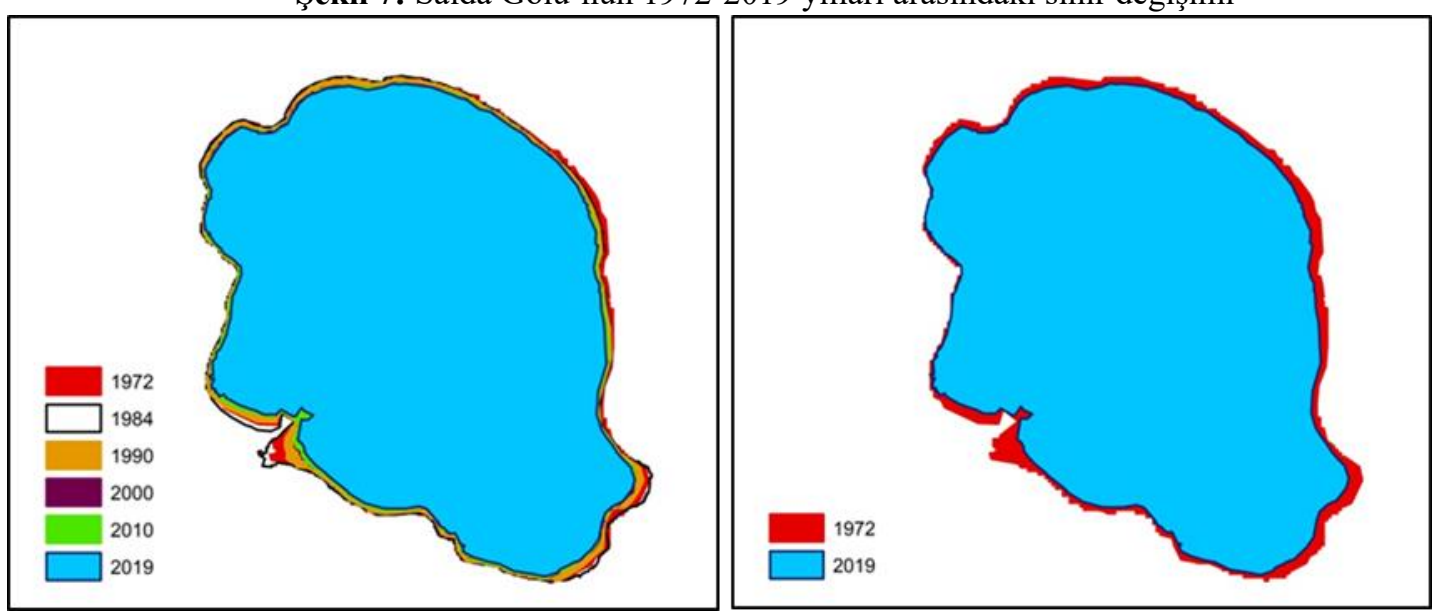

Elde edilen göl yüzey alanları Calculate Geometry aracıyla $\mathrm{km}^{2}$ cinsinden hesaplanmıştır. Sonuç olarak göl yüzey alanı 1972 yılında 45,43 km², 1984 yılında 45,82 km², 1990 yılında $44,65 \mathrm{~km}^{2}, 2000$ yılında 42,95 km², 2010 y1lında 43,11 km² ve 2019 y1lında 42,58 km² olarak hesaplanmıştır (Şekil 8).

Şekil 8: Salda Gölü'nün yüzey alanının yıllara göre değişimi $\left(\mathrm{km}^{2}\right)$

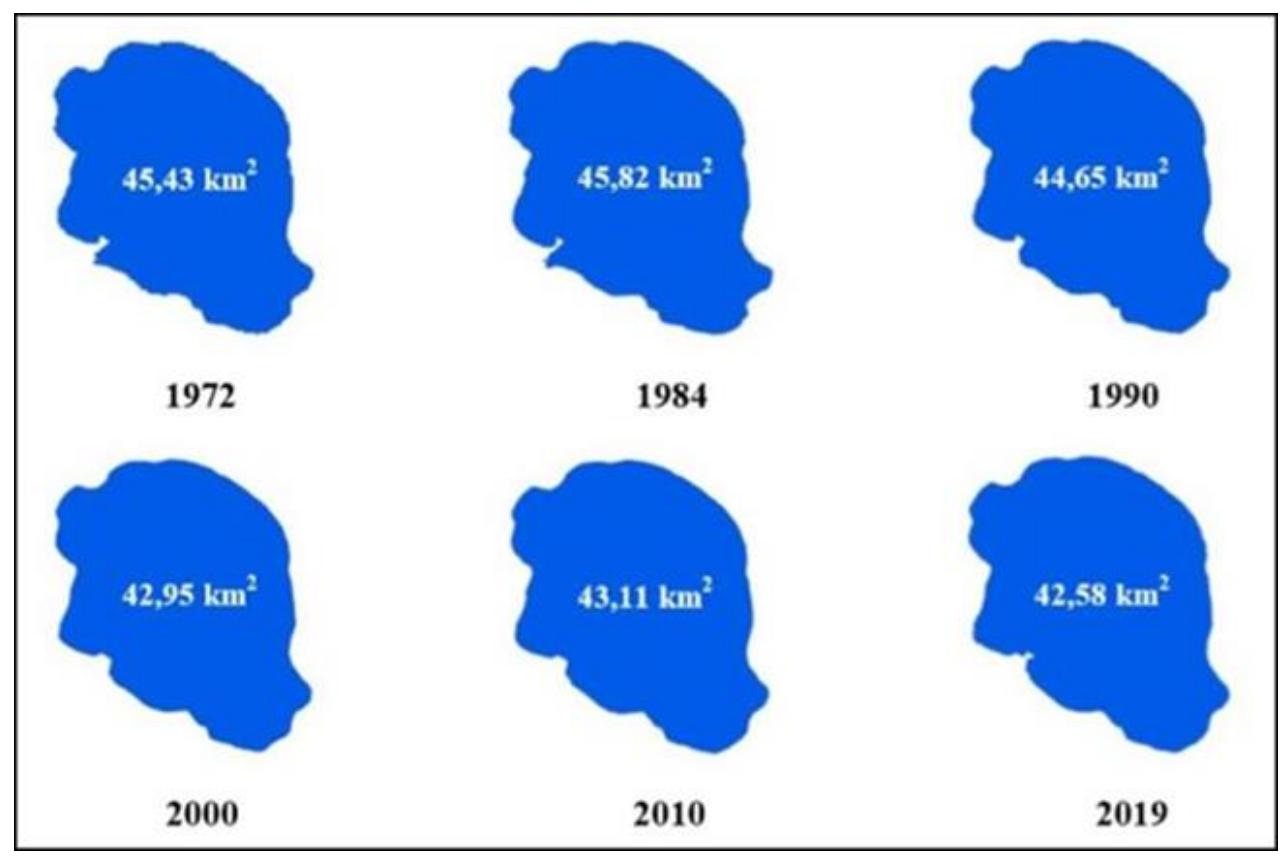

Göl yüzey alanındaki değişim 1972 yılındaki göl sınırları esas alınarak oransal olarak incelendiğinde ise değişim şu şekildedir;

- $\quad$ 1972-1984 yıllarında göl alanında \% 0,9 oranında büyüme,

- $\quad$ 1984-1990 yıllarında \% 2,6 küçülme,

- $\quad$ 1990-2000 yıllarında \% 3,8 küçülme,

- 2000-2010 yıllarında öncesindeki 10 yıla göre \% 0,4 büyüme fakat 1972 yılına göre \% 3,4 küçülme,

- 2010-2019 yıllarında \% 4,6 küçülme şeklindedir. Sonuç olarak 1972-2019 yılları arasında göl alanında \% 4,6 oranında küçülme meydana gelmiştir (Şekil 9). 
Şekil 9: Göl Yüzey Alanında Oransal Değişim Grafiği



Son olarak 1998-2015 yılları arasındaki yıllık ortalama göl seviyesi verisi ile 1998-2015 yılları arasındaki Ekim ayı ortalama göl seviyesi verisi aynı grafik üzerinde karşılaştırılmıştır (Şekil 10). Ekim ayı verisinin incelenme sebebi göl yüzey alanı değişimi analizi için kullanılmış olan uydu görüntülerinin Ekim ayına ait olmasıdır. Ayrıca kış yağışlarının etkili olduğu bölgelerde, sıcak ve kurak yaz aylarından sonra gelen Eylül-Ekim aylarında göl seviyesi genellikle en düşük seviyeye ulaşmakta ve mevsimsel dalgalanmaların olmadığı gerçek su seviyesi ortaya çıkmaktadır.

Şekil 10: Salda Gölü’nün 1998-2015 yılları arasındaki göl seviyesi değişimi grafiği (m)

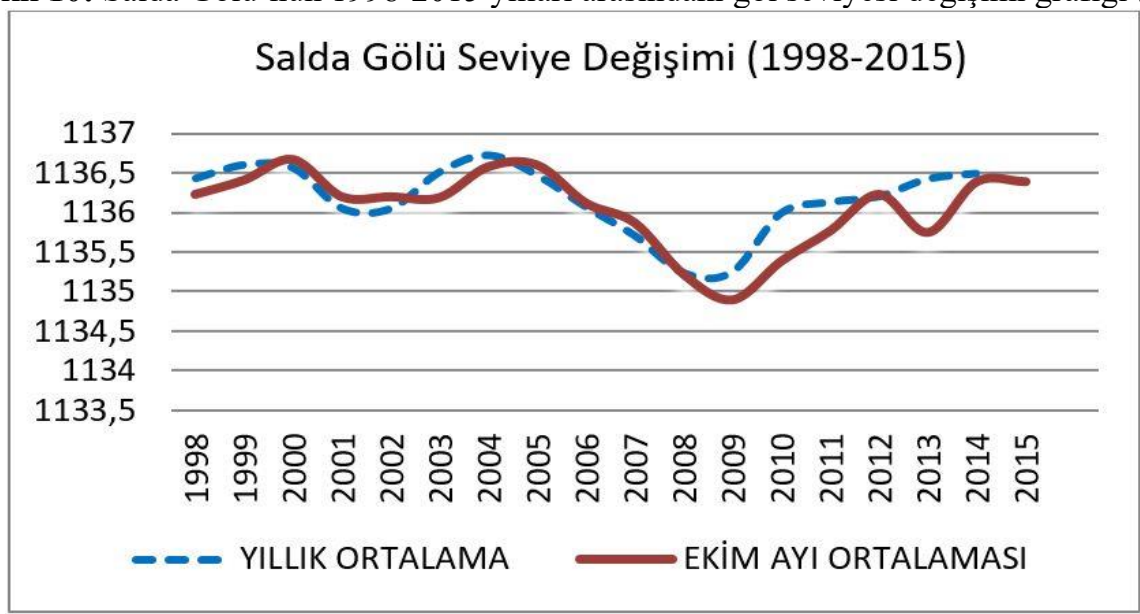

Şekil 10'da yer alan grafik incelendiğinde şu çıkarımlara ulaşılmıştır; yıllık ortalama ve Ekim ay1 göl seviyesi uzun yıllar ortalamasına bakıldığında 2008-2009 yılında en düşük seviyededir (1134-1135 m). Akdeniz Bölgesi'nde yer alan ve genel itibariyle su seviyesi iklim koşullarına bağlı bir göl olan Salda Gölü havzasında 2008 yılı yăğş tutarlarına baktığımızda her üç istasyonda da uzun yıllar ortalamasının altında kalmaktadır (Şekil 4). İklim koşullarındaki değişimine bağlı sıcaklıklardaki artışın buharlaşmayı kuvvetlendirmesiyle su kaybı daha artmaktadır. Ayrıca yaz aylarında göl çevresindeki tarımsal faaliyetlerde su kullanımının bilinçsiz ve kontrolsüz bir şekilde gerçekleşmesiyle, gölü besleyen yeraltı suyu seviyelerindeki değişim göl seviyesi ortalamasını da düşürmektedir. 


\section{SONUÇ ve ÖNERILER}

İklim koşullarındaki değişikliğin Salda Gölü'ne etkisini belirleyebilmek amacıyla istatistiksel yöntemler ile iklim verileri ve uydu görüntüleri analiz edilmiş, arazi çalışmalarıyla elde edilen bulgular desteklenmiştir. Elde edilen sonuçlara göre çalışma alanında son 50 yılda yıllık ortalama sıcaklıklarda istatistiksel olarak bir artış trendi olduğu tespit edilmiştir. 2000'li yıllar sıcaklık koşullarındaki değişimin başlangıcı olarak tespit edilmiştir. Buna bağlı olarak 2000 yılından itibaren başlayan bu değişim uydu görüntüleri ile görsel ve sayısal olarak da belirlenmiştir. Son 48 yılda göl yüzey alanında alansal olarak küçülme ve değişim gözlenmiştir. Mann Kendall Sıra Korelasyon testi sonucunda elde edilen sıcaklıklardaki artış eğilimi ve değişim, mekânsal analiz sonucu elde edilen yüzey alanı ve sınır değişimini anlamlandirmaktadir.

Bu değişimde en büyük etken gölün doğal yapısının gerek iklim koşullarındaki değişim gerekse antropojenik süreçlerin etkisiyle bozulmasıdır. 1972 yılında 45,43 km²'lik bir alana sahip olan göl yüzeyi, 2019 y1lında 42,58 km²'ye düşmüştür. Salda Gölü kapalı havza özelliğinde olduğundan gölün beslenme kaynakları sürekli ve mevsimlik akış gösteren dereler ve yeraltı suyudur. Arazi çalışmalarından elde edilen bulgulara göre; son yıllarda gölü besleyen ana dereler üzerine baraj ve göletler inşa edilmiştir. Ayrıca tarımsal faaliyetlerde kullanılmak üzere gölü besleyen yeraltı suları kontrolsüz bir şekilde tüketilmeye başlanmıştır. Gölün beslenme kaynaklarındaki kesintiler ve artan sıcaklıkların etkisiyle şiddetli buharlaşma ve beraberinde kuraklık sorunu, göl havzasındaki alan kaybının başlıca sebepleri olarak gösterilebilir. Akdeniz Havzası'nda yer alan, ulusal ve uluslararası ekolojik değere sahip hassas göllerden birisi olan Salda Gölü'nde iklim değişikliğinin etkileri son 20 yılda net bir biçimde gözlemlenmektedir. Sürdürülebilir bir sulak alan yönetimi için karar vericiler tarafından Salda Gölü'nde iklim değişikliğine adaptasyon ve uyum süreci başlatılmalıdır.

\section{KAYNAKÇA}

Baylan, K. \& Ustaoğlu, B. (2020). Emberger biyoiklim sınıflandırmasına göre Türkiye'de Akdeniz biyoiklim katlarının ve alt tiplerinin dağılışı. Ulusal Çevre Bilimleri Araştırma Dergisi, 3(3), 158-174. https://dergipark.org.tr/tr/pub/ucbad/issue/54856/746927

Braithwaite, C. \& Zedef, V. (1994). Living hydromagnesite stromatolites in Turkey. Journal of Sedimentary Geology, 1-2(1-5). https://doi.org/10.1016/0037-0738(94)90051-5

Braithwaite, C.J.R. \& Zedef, V. (1995). Hydromagnesite stromatolites and sediments in an alkaline lake, Salda Lake Turkey. Journal Sedimentary Research, (5), 991-1002.

Çaldırak, H., Kurtuluş, B., Canoğlu, C. M. \& Tunca, E. (2017). Assessment of heavy metal contamination and accumulation patterns in the coastal and deep sediments of lake Salda, Turkey. Fresenius Environmental Bulletin, 25(12), 8047-8061.

Çetin, B. (2002). Salda Gölü Havzası'nın fiziki coğrafyası (physical geography of Salda Lake Basin). (Yayınlanmamış yüksek lisans tezi). Atatürk Üniversitesi, Sosyal Bilimler Enstitüsü, Erzurum, Türkiye.

Danladia, I. \& Ön, S. (2015). Solar forcing of climate change during the last millennium: Lake Salda (Burdur, Turkey) sediment records. 2nd Coastal and Marine Geology Symposium and IODP-ECORD Meeting. İstanbul, Türkiye

Delju, H. A., Ceylan, A., Piguet, E. \& Rebetez, M. (2012). Observed climate variability and change in Urmia Lake Basin, Iran. Journal of Theory Apply Climatoly, (1-2), 285-296. DOI: $10.1007 / \mathrm{s} 00704-012-0651-9$

DKMP, (2013). Sulak alanlar. Erişim Tarihi: 1 Mayıs 2020, https://www.saldagolu.com/wpcontent/uploads/Belgeler/Sulak_Alanlar_Kitabi_SaldaGoluCom.pdf. 
Doulgeris, C. P. \& Kapsomenakis, J. (2016). Impacts of climate change on the hydrology of two natura 2000 sites in Northern Greece. Journal of Regional Environmental Change, (16), 1941-1950. DOI: 10.1007 / s10113-015-0857-3.

Fural, Ş., Cürebal. İ. \& İnan, F. (2019). Elmalı'da (Antalya) yağışın tetiklediği sel taşkın ve çamur akıntısı. Jeomorfolojik Araştırmalar Dergisi, (3), 49-61. Retrieved from https://dergipark.org.tr/tr/pub/jader/issue/49634/633790

IPCC, (2014). Climate Change 2014: Synthesis Report. Contribution of Working Groups I, II and III to the Fifth Assessment Report of the Intergovernmental Panel on Climate Change [Core Writing Team, R.K. Pachauri and L.A. Meyer (eds.)]. 15 Eylül 2020, https://www.ipcc.ch/site/assets/uploads/2018/02/SYR_AR5_FINAL_full.pdf

İkiel, C. \& Ustaoğlu, B. (2011). Sakarya deltasının doğu kesiminde kıyı çizgisi değişiminin coğrafi bilgi sistemleri ve uzaktan algılama yöntemleriyle analizi. İçinde Ed. D. Ekinci, Fiziki Coğrafya Araştırmaları, Sistematik ve Bölgesel (s. 483-492). İçinde İstanbul: Türk Coğrafya Kurumu Yayınları No:5.

Kale, M., Ataol, M. \& Erkal, T. (2018). Eber ve Akşehir göllerinde 1990-2016 yılları arasında gerçekleşen alansal değişimler. TÜCAUM Uluslararası Coğrafya Sempozyumu içinde (s.859-872). Ankara.

Kantarcı, M. (2009). Isınma - kuraklaşma sürecinin göller bölgesindeki durumu ve etkileri üzerine ekolojik bir değerlendirme. Turkish Journal of Forestry, 9 (2) , 1-34 . Retrieved from https://dergipark.org.tr/tr/pub/tjf/issue/20891/224298

Kazanc1, N. Girgin, S. \& Dügel, M. (2004). On the limnology of Salda Lake, a large and deep soda lake in Southwestern Turkey: future management proposals. Journal of Aquatic Conservation Marine and Freshwater Ecosystems, 14(2), 151-162. DOI: 10.1002 / aqc.609

Kazanc1, N., Girgin, S. \& Dügel, M. (2008) Climate change impacts on lake Bafa in mediterranean climate region in Turkey. Conference: BALWOIS içinde (ss.1-6), Ohri.

NASA. (2020). Jez like Mars. Erişim tarihi: 1 Eylül 2020, https://earthobservatory.nasa.gov/images/147041/jez-like-mars.

Orhan, O. (2014, Temmuz 23). Konya Kapalı Havzası'nda uzaktan algilama ve cbs teknolojileri ile iklim değişikliği ve kuraklık analizi. (Yüksek lisans tezi). Aksaray Üniversitesi Fen Bilimleri Enstitüsü, Aksaray, Türkiye

OSİB. (2013). Salda gölü (Salda lake). Erişim tarihi: 1 Mayıs 2020, https://issuu.com/yildiraylise/docs/salda_kitap

Schmidt, H. (1987). Turkey's Salda Lake: a genetic model for Australia's Newly Discovered Magnesite Deposits. Journal of Industrial Minerals, 19-29.

Tabari, H., Hosseinzadehtalaei, P., Ezani, A. \& Some, S. (2012). Shift changes and monotonic trends in autocorrelated temperature series over Iran. Theoretical and Applied Climatology, 109(1-2), 95-108. DOI:10.1007 / s00704-011-0568-8.

TMMOB. (2020). Salda gölü raporu. Erişim tarihi: 1 Eylül 2020, http://www.tmmob.org.tr/sites/default/files/tmmobsaldagoluraporu.pdf

Turoğlu, H. \& Aykut, T. (2019). Ergene nehri havzası için hidromorfometrik analizlerle taşkın duyarlılık değerlendirmesi. Jeomorfolojik Araştırmalar Dergisi, (2), 1-15. Retrieved from https://dergipark.org.tr/tr/pub/jader/issue/44568/538941

Türkeş, M. (1996 ). Spatial and temporal analysis of annual rainfall variations in Turkey. International Journal of Climatology, 16, 1057-1076.

Ustaoğlu, B. (2012). Matlab'da iklim veri analizi ve uygulamaları (climate data analysis and applications in Matlab). İstanbul: Anka Matbaa. 
Ustaoğlu, B. (2013). Trend analysis of annual mean temperature data using Mann-Kendall Rank Correlation Test in Catalca-Kocaeli peninsula, northwest of Turkey for the period of 1970-2011. IBAC 2012 Book of Proceedings, (276-287).

Ustaoğlu, B. \& Uzun, A. (2018). Akdeniz bölgesinde (Türkiye) yetiştirilen tarım ürünlerinin özel iklim isteklerine uygun arazilerin ağırlıklı çakıştırma analizi ile belirlenmesi. International Journal of Human Sciences, 15(4), 2433-2453. DOI: 10.14687/jhs.v15i4.5573

Varol, S., Davraz, A., Şener, Ş., Şener, E., Aksever, F., Kırkan, B. \& Tokgözlü, A. (2018). Application of a conceptual water budget model for Salda lake, (Burdur/ Turkey). Journal of Engineering Sciences and Design, (1), 29-37. https://doi.org/10.21923/jesd.374412

Varol, S., Davraz, A., Şener, Ş. \& Şener, E. (2020). Determining the lake protected zones using GIS-based Drastic model to groundwater vulnerability in Salda lake basin (Burdur/Turkey). Turkish Journal of Earth Sciences, (29), 747-763. DOI: 10.3906/yer1907-27

Yiğitbaşıoğlu, H. (1995). Seyfe gölü ekosistemi. Türkiye Coğrafyası Araştırma ve Uygulama Merkezi Dergisi, (4), 147-169.

Yue, S. Pilon, P. \& Cavadias, G. (2002). Power of the Mann-Kendall and Spearman's rho tests for detecting monotonic trends in hydrological series. Journal of Hydrology, 259(1-4), 262-263. https://doi.org/10.1016/S0022-1694(01)00594-7. 